\title{
A Future Micro-grid Implementation based on Renewable Distributed Resources for a Clean Green Energy Production
}

\author{
F. Marín ${ }^{1}$, A. B. Rey ${ }^{2}$, A. Guerrero ${ }^{3}$ and F. de A. Ruz ${ }^{1}$ \\ ${ }^{1}$ Department of Electrical Engineering \\ E.T.S.I.I., Technical University of Cartagena \\ Campus of Muralla del Mar, 30202 Cartagena (Spain) \\ Phone:+0034 968 325481, e-mail: pentxo.marin@upct.es, paco.ruz@upct.es \\ ${ }^{2}$ Department of Electronics, Comp. Tech. \& Projects \\ E.T.S.I.T., Technical University of Cartagena \\ Campus of Muralla del Mar, 30202 Cartagena (Spain) \\ Phone:+0034 968 325928, e-mail: alexis.rey@upct.es \\ ${ }^{3}$ Department of Automatics and Systems \\ E.T.S.I.I., Technical University of Cartagena \\ Campus of Muralla del Mar, 30202 Cartagena (Spain) \\ Phone:+0034 968 325398, e-mail: antonio.guerrero@upct.es
}

\begin{abstract}
Some problems can appear using Distributed Generation (DG). A better solution for clean green energy production can be made through a cluster of Renewable Distributed Resources (DR) -such as PV cells, wind turbines, fuel cells and others- and its associated loads. This is known as micro-grid, an Edison's concept with a remarkable future in Kyoto's Protocol era. In spite of this strategic point of view, two main stages of the micro-grid can be taken into account: grid-connected and stand alone (intentioned island). In addition, the improvement of the local reliability has an enormous importance. Furthermore, it is clearly critical to be able to use the waste heat by placing the DR near the heat load. In conclusion, it will have implemented a Combined Heat Power (CHP).
\end{abstract}

\section{Key words}

Micro-grid, DR, clean green energy production, DG, CHP

\section{Introduction}

It is obviously certain that environmental and electrical laws, economics and technology are changing the utility business. The real situation goes to smaller, more energy efficient, more reliable and more flexible power systems.

There are some pilot experiences in micro-grids in the US and in Europe [1], but it will have passed between five and ten years till it can be known if the above changes are realistic. Therefore it is not very important the penetration of micro-grids in Spain. It is known that Iberdrola S.A. is developing a special type of micro-grid in Basque Country [2].
Distributed generation take a comprehensive collection of prime mover technologies, such as gas turbines, microturbines, photovoltaic, fuel cells, wind power and internal combustion engines. Some of them, such as photovoltaic and wind power, need an inverter to interface with the power system. These emerging technologies have lower emissions, something that says the Kyoto's Protocol.

Massive application of single distributed generators could cause more problems than it might solve. Micro-grid is a better approach: it views a cluster of generators and associated loads as a subsystem [1]. It allows for local control of DG and reduces or eliminates the need for central delivery. During faults, the micro-grid can disconnect itself from the power system to isolate its loads, maintain good level of service and eliminate micro-grid's integrity problems. Stand-alone stage has the potential to provide a higher local reliability than that provided by the utility. The size of emerging generation technologies permits generators to be placed optimally in relation to heat loads. Such applications can multiply by two the overall efficiency of the systems.

Most current micro-grid implementations combine generators and loads, allow to intentional stand-alone stage and try to use the available waste heat to improve the overall efficiency.

\section{Clean Green Energy Production}

DG applications prefer natural-gas technologies due to the potential of low air emissions. As a result the engine technology has been driven by economic and environmental pressures for power-density 
improvements, increased fuel efficiency and reduced emissions.

More existing power plants, central or distributed, deliver electricity to final users at an overall fuel-to-electricity efficiency around $30 \%$. This represents a loss of around $70 \%$ of the primary energy provided to the generator. To reduce this loss it is necessary to increase the fuel-toelectricity efficiency of the generation plant and use the waste heat. This use of waste heat -co-generation or CHP- implies an integrated energy system. Heat, in the form of hot water or steam- can not be easily transported long distances, so CHP systems provide heat for local use. Because electricity is more readily transported than heat, generation of heat close to the location of the heat load will usually make more sense than generation of heat close to the electrical load. For stationary energy users needing both electricity and useful heat there are two basic systems available: separate generation of electricity and heat, and combined heat and power (CHP) systems located near the heat load.

\section{Main challenges}

The development of the low voltage micro-grids is not a cool approach, such as it has been mentioned in the above paragraphs. The novelty of this communication is to give some control strategies for a 3-phase inverter working as a power conditioner for a set of PV cells. There will be some loads that will be supplied by these alternative prime movers -in two stages: grid-connected or UPS- or by the utility in grid-connected mode. In the immediate future it would be desirable to implement a cluster of micro-generators, loads, storage devices, control strategies and protection to obtain experimental results. Nowadays it can be said that it is an ambitious project that is arising in our group. In addition, the microgrid platform will serve to keep in contact to other Spanish [2], European [3] and World wide R\&D groups [1].

Through the current R\&D initiative, interaction between the micro-grid and the power system will be studied deeply. On the other hand, the basic and specific objectives of our project are as follows:

$\checkmark \quad$ To give a simulation environment for doing research through a theoretical point of view of the technician skills

$\checkmark \quad$ To develop and implement a low voltage micro-grid system, which can provide plug and play and peerto-peer services, [4]-[5], based on micro-generation technologies such as PV cells and wind power, and storage based on batteries with inverter connected to ACLV system. In addition, it will be possible to employ a fuel cell and a flywheel

$\checkmark$ To identify the requirements needed by the power system equipments and the managing systems to work in these circumstances.

$\checkmark$ To develop some devices, systems and solutions from the specifications. $\checkmark \quad$ To analyse the conditions of the electric market to implement this type of solutions [1].

In order to carry out all these tasks, it is important to know that there are a lot of public institutions and private organizations giving support to us, i.e. Universidad Politécnica de Cartagena, the Council of Molina de Segura, ARGEM, Fundación Sierra Minera, Wind Farm from La Unión S.L., INext S.L. It will be proposed an invitation to Navantia -Power Systems Division- for working together because a $250 \mathrm{~kW}$ fuel cell is located in its installation.

\section{Micro-grid layout}

The electric power system layout will allow us to identify some associate problems that will appear with the penetration of DG in the low voltage network.

The micro-grid platform will be set up by some microgeneration cells connected to a specific purpose low voltage network, located in our installations:

$\checkmark \quad$ Simulation tools and DG models. At the beginning, it will be necessary to start with existing tools and models, that does research about electric and dynamic effects in micro-grids

$\checkmark$ Distributed Resources: two 3-phase emulated 5 KVA wind turbines -one of them asynchronous generator based and the other a synchronous generator basedwith emulation for the wind speeds -real data obtained from a wind farm called Parque Eólico La Unión S.L. -between 3 and $15 \mathrm{~m} / \mathrm{s}$; one 3-phase PV system, where the PV cell is emulated by a programmable DC-source whose maximum power is $3 \mathrm{kVA}$ and with a controlled inverter - data from real PV system located in Mina Las Matildes, El Beal, owned by Fundacion Sierra Minera- which can be programmed through a PC and can improve the synchronization between the micro-grid and the utility grid; and finally one generator powered by diesel whose maximum power delivered is $35 \mathrm{kVA}$

$\checkmark \quad$ Storage: to solve some storage problems, it will have some batteries -with controlled inverters- connected to AC bus bar, flywheels and a fuel cell

$\checkmark$ Loads: there will be three resistor groups of $10 \mathrm{~kW}$ each one which will connect to the DR.

$\checkmark$ Equipment of plugging, measurement and control: protection devices, inverters, improvement-qualityenergy devices in micro-grid, measurements devices and others.

\section{Control in a micro-grid}

Vector control is used in both cases, where the decouple regulation in $d-q$ reference frame is exerted [6].

A) Three-phase grid-connected inverter (current source control) 
The block diagram of the control is depicted in Fig. 1. A PI regulator is used for the DC voltage in the outer loop, meanwhile a hysteresis control is used for the line currents in the inner loop. An utility observer is used for synchronization with the mains.

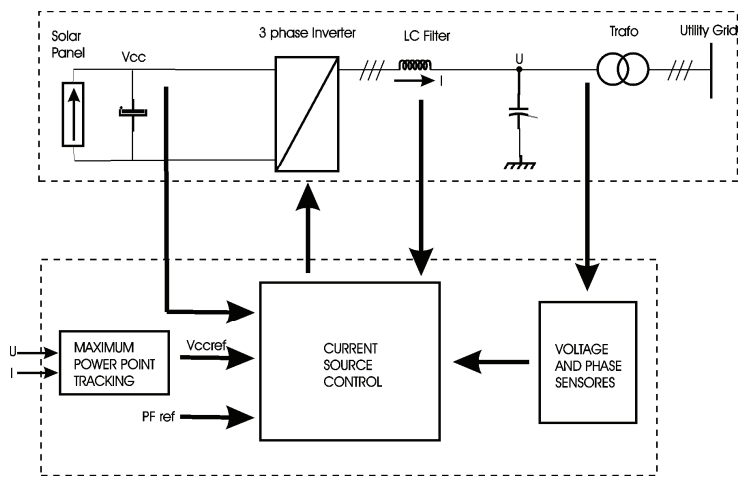

Fig. 1. Block diagram of the control of the grid-connected 3phase inverter

\section{B) Three-phase UPS system (voltage source control)}

The block diagram of the control is depicted in Fig. 2. A PI regulator is used for the load voltage in the outer loop, meanwhile a hysteresis control is used for the capacitor currents in the inner loop.

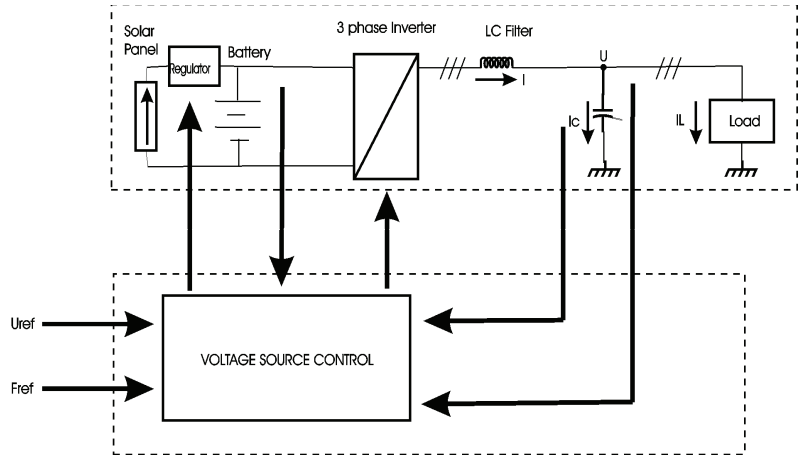

Fig. 2. Block diagram of the control of the 3-phase UPS system

\section{Simulations}

Some simulations are made in order to show the behaviour of the control of the two situations described above:

\section{A) 3-phase grid-connected inverter}

The simulation parameters are:

$\mathrm{I}_{\text {panel }}=10 \mathrm{~A}$ (for a specific irradiance)

$\mathrm{Vcc}_{\text {ref }}=240 \mathrm{~V}(\mathrm{P}=2.4 \mathrm{~kW})$

$\mathrm{L}_{\text {line }}=1 \mathrm{mH}$

$\mathrm{R}_{\text {line }}=1 \Omega$

$\mathrm{C}=100 \mu \mathrm{F}$ (delta connection)

$\mathrm{U}_{\text {utility grid }}=31.8 \mathrm{~V}($ trafo ratio $=1: 6.9)$

$\mathrm{PF}_{\mathrm{ref}}=1$ (open loop)
Transformation is needed for isolation and for increasing the voltage.

Some variables of the simulation are displayed in Fig. 3.

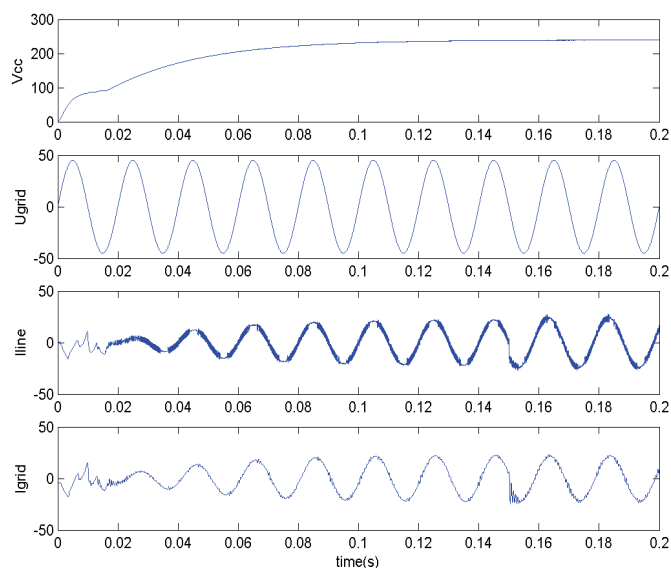

Fig. 3. Evolution of the main variables in the 3-phase grid connected system for phase 1

At the top of the figure, it can be seen the evolution of the voltage at the link capacitor $-\mathrm{V}_{\mathrm{CC}^{-}}$in time. It evolves from 0 to $240 \mathrm{~V}$ and stabilizes at $0.2 \mathrm{~s}$.

Following, the grid voltage is modelled as a perfect sine wave with rms value of $31.8 \mathrm{~V}$ and with fundamental frequency of $50 \mathrm{~Hz}$.

Following, the line current is depicted. After a transient period of time of $0.12 \mathrm{~s}$ approximately, the line current is almost a sine wave (plus harmonics) in perfect synchronism of phase and frequency with the utility voltage until $0.15 \mathrm{~s}$.

When a sudden step of $-20 \mathrm{~A}$ at $\mathrm{Iq}_{\mathrm{ref}}$ is made at $0.15 \mathrm{~s}$, the power factor of the connection decreases, and then, the utility voltage and the line current for phase 1 are not in synchronism of phase anymore. This means that the controller is capable of controlling the power factor of the connection.

Finally, the grid current is closer to a pure sine wave due to the action of the $\mathrm{L}$ filter of the isolated transform.

In Fig. 4, it is shown the evolution of the currents in the transform domain -vector control-. In spite of the harmonics, it can be seen a circular evolution which means that the 3-phase currents lags 120 degrees one from each other. 


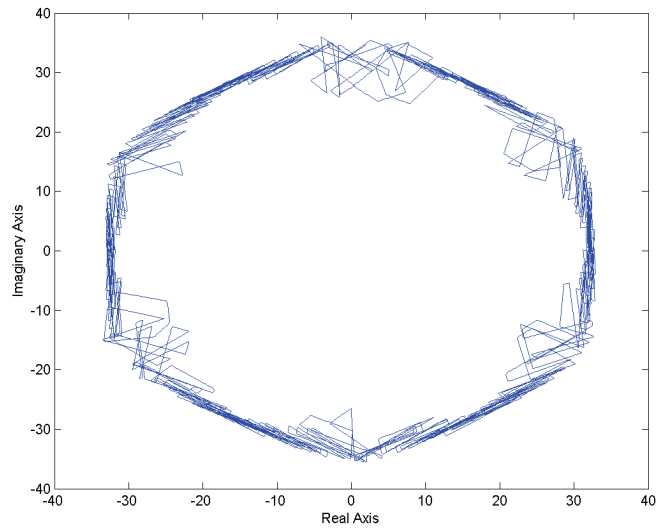

Fig. 4. Evolution of the line currents of the 3-phase grid connected system in the transform domain

B) 3-phase UPS system

The simulation parameters:

$\mathrm{I}_{\text {panel }}=5 \mathrm{~A}$ (for a specific irradiance)

$\mathrm{Vcc}_{\text {battery }}=240 \mathrm{~V}\left(\mathrm{P}_{\max }=1.2 \mathrm{KW}\right)$

$\mathrm{L}_{\text {line }}=1 \mathrm{mH}$

$\mathrm{R}_{\text {line }}=1 \Omega$

$\mathrm{C}=300 \mu \mathrm{F}$ (Y connection)

$\mathrm{U}_{\text {load ref }}=31.8 \mathrm{~V}($ trafo ratio $=1: 6.9)$

$\mathrm{F}_{\text {ref }}=50 \mathrm{~Hz}$

$\mathrm{R}_{\text {load }}=100 \Omega$

$\mathrm{L}_{\text {load }}=5 \mathrm{mH}$

Transformation is also needed for isolation and for increasing the voltage.

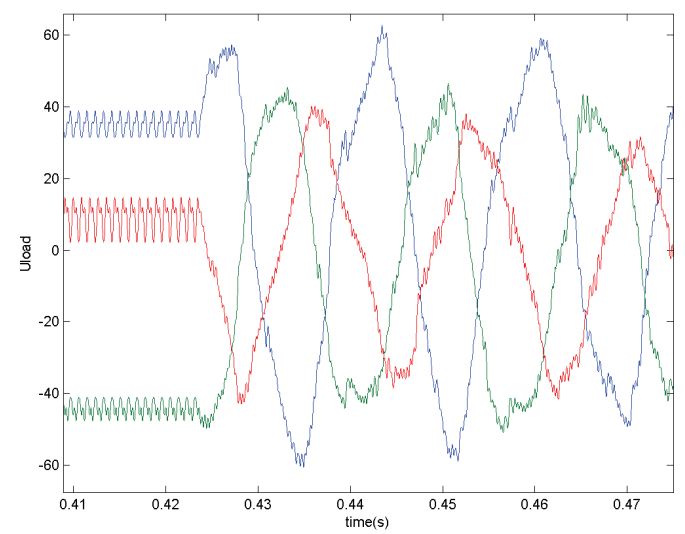

Fig. 5. Evolution of the of the 3-phase load voltages for the UPS system

In spite of the presence of the harmonics, it can be seen in Fig. 5, that the output 3-phase voltages follows the reference of amplitude and frequency.

\section{Conclusions}

An introduction of the micro-grids has been realized at the beginning of this paper. The challenges of ours have been proposed in the second point and it is being known that is our initial step in this R\&D field. Some ideas about clean green energy production have been introduced in the third point. Furthermore the layout of the system has been presented, the vector control established and finally some simulations about two real situations -a 3-phase grid connected PV cell and a PV cell working as a 3-phase UPS- have been developed.

This R\&D field must be improved in the next months and a lot of joints are being got between our University and public and private corporations. To work with the Spanish, the EU and the US R\&D groups would be a great idea in a near future.

\section{Acknowledgement}

This work has been supported by the Ministry of Education and Culture of Spain through a national R\&D fellowship whose identification is ENE2005-09375-C03$01 / \mathrm{CON}$. Other private corporations have been collaborating during these months -Fundación Sierra Minera, Wind Farm La Unión S.L. and INext S.L.-.

\section{References}

[1] R. Lasseter, A Akhil, C. Marnay, J. Stephens, J. Dagle, R. Guttromson, A. S. Meliopoulos, R. Yinger and J. Eto, "White Paper on Integration of Distributed Energy Resources -The CERTS MicroGrid Concept". LBNL50829, Office of Power Technologies of the US Department of Energy, Contract DE-AC03-76SF00098, April 2002.

[2] Cluster de Energía del País Vasco, "Proyecto de experimentación de una microrred integrada en la red de distribución", in EnergiaBerria, nº 16 , pp. 22-23, December 2004

[3] D. Georgakis, S. Papathanassiou, N. Hatziargyriou, A. Engler and Ch. Hardt, "Operation of a Prototype Microgrid System Based On Microsources equipped with fast-acting power electronics interfaces", in Proc. PESC 2004, vol. 1, pp. 4285-4290.

[4] R. H. Lasseter and P. Paigi, "Microgrid: A conceptual solution", in Proc. PESC 2004, vol. X, pp. 2521-2525

[5] R. H. Lasseter and P. Paigi, "Microgrid: A conceptual solution", in IEEE PES Winter Meeting, 2002, vol. X, pp. 305-308

[6] P. Korondi, H. Hashimoto, "Park Vector Based Sliding Mode Control of UPS with Unbalanced and Nonlinear Load", in Workshop on Variable Structure Systems VSS'98, 1998. 